\title{
Output voltage regulation of synchronous generator using PSO algorithm-based PI controller
}

\author{
Fatiha Habbi, Nour El Houda Gabour, El Ghalia Boudissa, M'hamed Bounekhla \\ Laboratory of electrical systems and control LABSET, Faculty of the Engineering Sciences, Saad Dahlab University, \\ Blida, Algeria
}

\begin{abstract}
Article Info
Article history:

Received Nov 23, 2020

Revised Apr 3, 2021

Accepted Apr 22, 2021

Keywords:

Automatic voltage

PI controller

PSO algorithm

regulatorAVR

Synchronous generator

ABSTRACT

In this paper a regulation of the terminal voltage of synchronous generator (SG) has been developed. Here, the nonlinear model of the SG is used directly without requirement for a linearized mathematical model of the generator. A proportional integral PI-controller is used to adjust the duty cycle of the DC chopper of step-down type for controlling the field voltage and consequently the output voltage of the generator. Furthermore, Particle swarm optimization (PSO) algorithm is employed as an optimization technique for tuning the optimal parameters of the PI controller (Kp and $\mathrm{Ki}$ ). This is achieved by the minimization of the quadratic output error between the reference voltage and the output voltage calculated from the adopted model at the same time. In order to test the performance of the PSO-PI controller, results are compared with the genetic algorithm (GA). Moreover, to reduce the overshoot resulting in the response of the terminal voltage, a varied reference voltage is adopted. Results obtained show the superiority of the varied reference voltage to decrease the overshoot versus the fixed reference voltage.
\end{abstract}

This is an open access article under the CC BY-SA license.

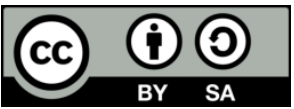

\section{Corresponding Author:}

Fatiha Habbi

Departement of Electrical and Electronics

Saad Dahleb University Blida 1

Blida, Algeria

Email: fatiha.habbi@gmail.com

\section{INTRODUCTION}

Numerous types of electric generators such as the linear, induction, permanent magnet and synchronous generators are used together in order to achieve the electric power generation. The latter ones are utilized almost exclusively in power systems as a source of electrical energy due to its accessibility for regulation.

Synchronous generator constant voltage at the generator terminals is necessary for satisfactory main power supply [1]. The output voltage can be affected by diverse disturbing factors such as random fluctuations in load, fault conditions. For this purpose, automatic voltage regulators (AVRs) are utilized for guarantying a stable terminal voltage of the synchronous generators by adjusting the excitation voltage.

Unfortunately, without any controller, the AVR system does not provide a suitable performance [2]. For this, several control methods have been studied and developed in the literature [3-5]. One of them is the proportional-integral-derivative (PID) and (PI) controllers which are widely used in industrial control applications and science like AVR systems [4], [6]. This popularity is due to their effectiveness, ease of implementation and their simple structure [7]. 
However, the tuning aspect of PID parameters is not easy for researchers and plant operators [8]. In this context, many different methods have been suggested to determine the parameters of PID controller. The most well-known method used in this target is the Ziegler-Nichols approach [9, 10]. Nevertheless, this method is complex and time consuming for systems with non-linearities such as synchronous generator [11]. Generally, it delivers a huge overshoot in the response of AVR system and is not suitable to achieve a fast dynamic response [10], [12].

In order to remedy these problems, different optimization methods have been adopted for tuning the optimal parameters of PID controller of an AVR system. Such algorithms included genetic algorithm (GA) [13], particle swarm optimization (PSO) [4], invasive weed optimization (IWO) algorithm [14], Artificial Bee Colony algorithm (ABC) [6], cuckoo search (CS) [10], and others.

Furthermore, an effective control of the terminal voltage of the synchronous generator requires an accurate model. Most of researchers have used transfer functions to represent the model of AVR system when the generator model is also represented with a transfer function, which differs between them to the order of the model. A low order (first and second-order) is used in [4], [13] and a high order is adopted in the works [15], [16]. To determine the transfer functions, a linearization is needed. In other words, a limited development is performed around the operating point. Therefore, the model is validated only around the operating point.

In this work, for output voltage regulation of synchronous generator, the nonlinear model of the SG is used directly without needing a linearized mathematical model of the generator. Also, a varied reference voltage is adopted in order to decrease the overshoot resulting in the response of the terminal voltage. For this study, a PI controller is used to vary the duty cycle of the DC chopper of step down type for controlling the excitation voltage and therefore the terminal voltage of the generator. In addition, the PSO algorithm is applied for obtaining the parameters of the PI-Controller. The performance of the PSO-PI controller is tested with the GA-PI controller. To verify the validity of the varied reference voltage, a comparison of the response of the terminal voltage using the varied and the fixed reference voltage is carried out in this paper.

\section{MODELLING OF SYNCHRONOUS GENERATOR}

The study was carried out on a salient-pole synchronous generator. Figure 1 shows the simplified structure of a salient-pole synchronous generator, which comprises three armature windings, one excitation or field winding and short circuited damper winding in each axis (d-axis and q-axis). In order to obtain the fundamental equations of a synchronous machine, the principal assumptions adopted are [17]:

- The three-phase stator windings are symmetrical and are sinusoidally distributed in space around the air-gap.

- $\quad$ Hysteresis effects are ignored.

- $\quad$ There is no magnetic saturation.

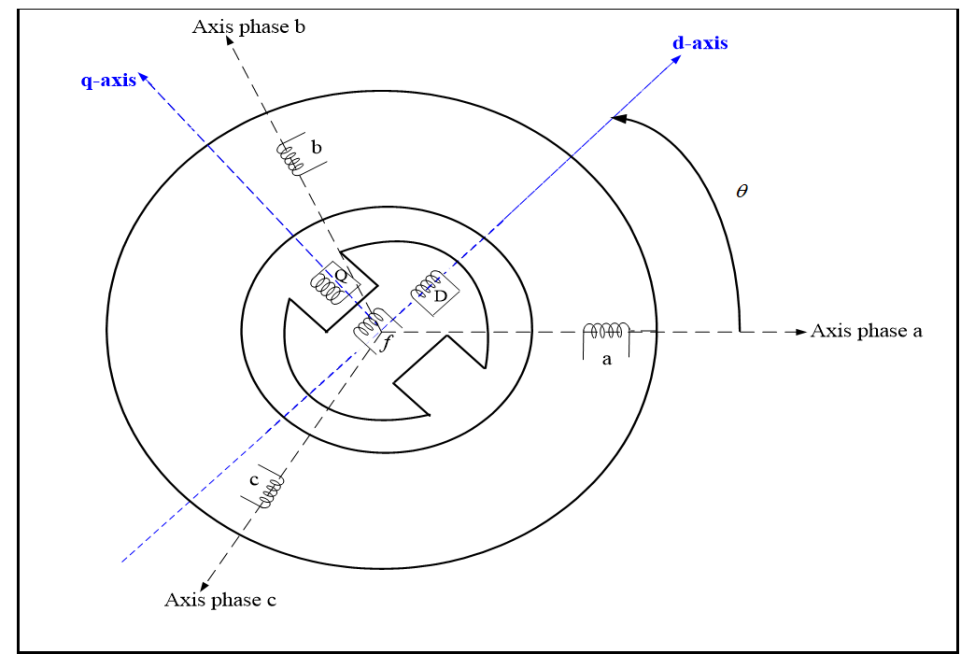

Figure 1. Synchronous generator windings with dampers.

Considering the generator convention for the stator windings, in the Park framework, the dynamic equations of a synchronous generator related to a reference linked to the rotor are written, as follow [18]: 


$$
\begin{aligned}
& V_{d}=-R_{s} I_{d}+\frac{d}{d t} \psi_{d}-\omega \psi_{q} ; V_{q}=-R_{s} I_{q}+\frac{d}{d t} \psi_{q}+\omega \psi_{d} ; V_{F}=R_{F} I_{F}+\frac{d}{d t} \psi_{F} ; \\
& 0=R_{D} I_{D}+\frac{d}{d t} \psi_{D} ; 0=R_{Q} I_{Q}+\frac{d}{d t} \psi_{Q}
\end{aligned}
$$

In which; $V, R, I, \omega$, and $\psi$ denote voltage, resistance, current, angular speed and flux linkage.s, $F, D, Q$ indicate armature, field and damper windings. Subscripts $d$ and $q$ stand for the direct and quadrature axes, respectively. The Flux linkage relationships are expressed as (2):

$$
\begin{aligned}
& \psi_{d}=-L_{d} I_{d}+M_{F d} I_{F}+M_{D d} I_{D} ; \psi_{q}=-L_{q} I_{q}+M_{Q q} I_{Q} ; \psi_{F}=L_{F} I_{F}+M_{F D} I_{D}-M_{F d} I_{d} \\
& \psi_{D}=L_{D} I_{D}+M_{F D} I_{F}-M_{D d} I_{d} ; \psi_{Q}=L_{Q} I_{Q}-M_{Q q} I_{q}
\end{aligned}
$$

where; $L_{F}, L_{D}$ and $L_{Q}$ are the inductances of the main field, direct and quadrature damper windings respectively. $L_{d}$ and $L_{q}$ are the inductances of the d-axis and q-axis stator winding. $M_{F d}, M_{F d}, M_{D d}$ and $M_{Q q}$ are the mutual inductances between the stator d-axis and the rotor main field, the rotor main field and the direct damper, the d-axis stator and the direct damper, finally between the q-axis stator and the transverse damper respectively.

The dynamic equations of the generator are given as follow (3):

$$
\begin{aligned}
& V_{d}=-R_{s} I_{d}+\omega L_{q} I_{q}-\omega M_{Q q} I_{Q}-L_{d} \frac{d}{d t} I_{d}+M_{F d} \frac{d}{d t} I_{F}+M_{D d} \frac{d}{d t} I_{D} \\
& V_{q}=-\omega \mathrm{L}_{\mathrm{d}} \mathrm{I}_{\mathrm{d}}-R_{s} I_{q}+\omega \mathrm{M}_{\mathrm{Fd}} \mathrm{I}_{\mathrm{F}}+\omega \mathrm{M}_{\mathrm{Dd}} \mathrm{I}_{\mathrm{D}}-L_{q} \frac{d}{d t} I_{q}+M_{Q q} \frac{d}{d t} I_{Q} \\
& V_{F}=R_{F} I_{F}-M_{F d} \frac{d}{d t} I_{d}+L_{F} \frac{d}{d t} I_{F}+M_{F D} \frac{d}{d t} I_{D} \\
& 0=R_{D} I_{D}+-\mathrm{M}_{\mathrm{Dd}} \frac{d}{d t} I_{d}+M_{F D} \frac{d}{d t} I_{F}+L_{D} \frac{d}{d t} I_{D} \\
& 0=R_{Q} I_{Q}-M_{Q q} \frac{d}{d t} I_{q}+L_{Q} \frac{d}{d t} I_{D}
\end{aligned}
$$

\subsection{Generator connected to an inductive load}

Let's consider that an inductive load is connected to the generator, after Park's transformation, the direct and quadrature components of the load voltage are represented by the following (4):

$$
\left[\begin{array}{c}
\mathrm{V}_{\mathrm{d}} \\
\mathrm{V}_{\mathrm{q}}
\end{array}\right]=\left[\begin{array}{cc}
-\mathrm{R}_{\mathrm{L}} & \omega \mathrm{L}_{\mathrm{L}} \\
-\omega \mathrm{L}_{\mathrm{L}} & -\mathrm{R}_{\mathrm{L}}
\end{array}\right]\left[\begin{array}{l}
\mathrm{I}_{\mathrm{d}} \\
\mathrm{I}_{\mathrm{q}}
\end{array}\right]+\left[\begin{array}{cc}
-\mathrm{L}_{\mathrm{L}} & 0 \\
0 & -\mathrm{L}_{\mathrm{L}}
\end{array}\right] \frac{\mathrm{d}}{\mathrm{dt}}\left[\begin{array}{l}
\mathrm{I}_{\mathrm{d}} \\
\mathrm{I}_{\mathrm{q}}
\end{array}\right]
$$

where; $R_{L}$ and $L_{L}$ are the resistance and the inductance of the load.

By combining the (3) and (4), the global equation of the generator is given by (5):

$$
[V]=[R][I]+[L] \frac{d[I]}{d t}
$$

where,

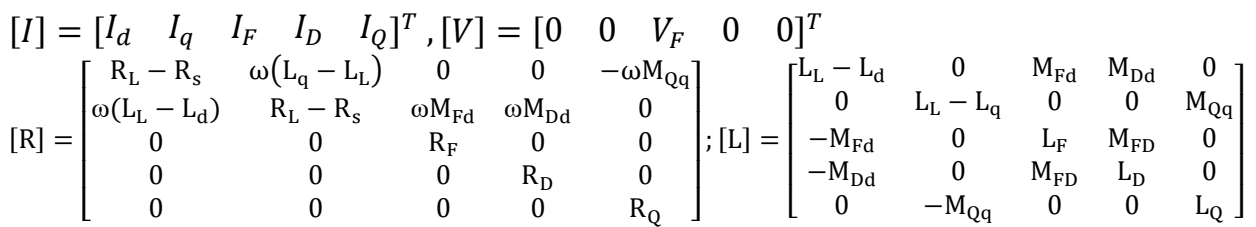

So the state Equation is (6):

$$
\frac{d[I]}{d t}=-[L]^{-1}[R][I]+[L]^{-1}[V]
$$

The stator terminal voltage $V_{a s}(t), V_{b s}(t)$ and $V_{c s}(t)$ can be derived numerically from the values of $V_{d}(t)$ and $V_{q}(t)$ by using the inverse Park transformation defined by (7) according to the machine's electrical angle $\theta[17]:$ 


$$
P(\theta)^{-1}=\sqrt{\frac{2}{3}}\left[\begin{array}{ccc}
\cos \theta & -\sin \theta & \frac{1}{\sqrt{2}} \\
\cos \left(\theta-\frac{2 \pi}{3}\right) & -\sin \left(\theta-\frac{2 \pi}{3}\right) & \frac{1}{\sqrt{2}} \\
\cos \left(\theta+\frac{2 \pi}{3}\right) & -\sin \left(\theta+\frac{2 \pi}{3}\right) & \frac{1}{\sqrt{2}}
\end{array}\right]
$$

Such that $V_{a b c}=P(\theta)^{-1} V_{d q o}$, by considering that the output voltage is well balanced, the homopolar component is null and by tacking, $\theta=\omega t+\theta_{0}$ the stator terminal voltage expressions $V_{a s}(t), V_{b s}(t)$ and $V_{c s}(t)$ are given by:

$$
\begin{aligned}
& V_{a s}(t)=\sqrt{\frac{2}{3}}\left(V_{d}(t) \cos \left(\omega t+\theta_{0}\right)-V_{q}(t) \sin \left(\omega t+\theta_{0}\right)\right) \\
& V_{b s}(t)=\sqrt{\frac{2}{3}}\left(V_{d}(t) \cos \left(\omega t+\theta_{0}-\frac{2 \pi}{3}\right)-V_{q}(t) \sin \left(\omega t+\theta_{0}-\frac{2 \pi}{3}\right)\right) \\
& V_{c s}(t)=\sqrt{\frac{2}{3}}\left(V_{d}(t) \cos \left(\omega t+\theta_{0}+\frac{2 \pi}{3}\right)-V_{q}(t) \sin \left(\omega t+\theta_{0}+\frac{2 \pi}{3}\right)\right)
\end{aligned}
$$

where,

$\omega$ : machine rotor speed in electrical radians/seconds.

$\theta_{0}$ : is the angle between the stator of phase ' $a$ ' and the rotor field axis ( $\mathrm{d}$ axis) at the instant $\mathrm{t}=0$.

\section{OUTPUT VOLTAGE REGULATION OF SYNCHRONOUS GENERATOR}

Figure 2 describes a block diagram to ensure the output voltage of the synchronous generator at the required value during load variations.

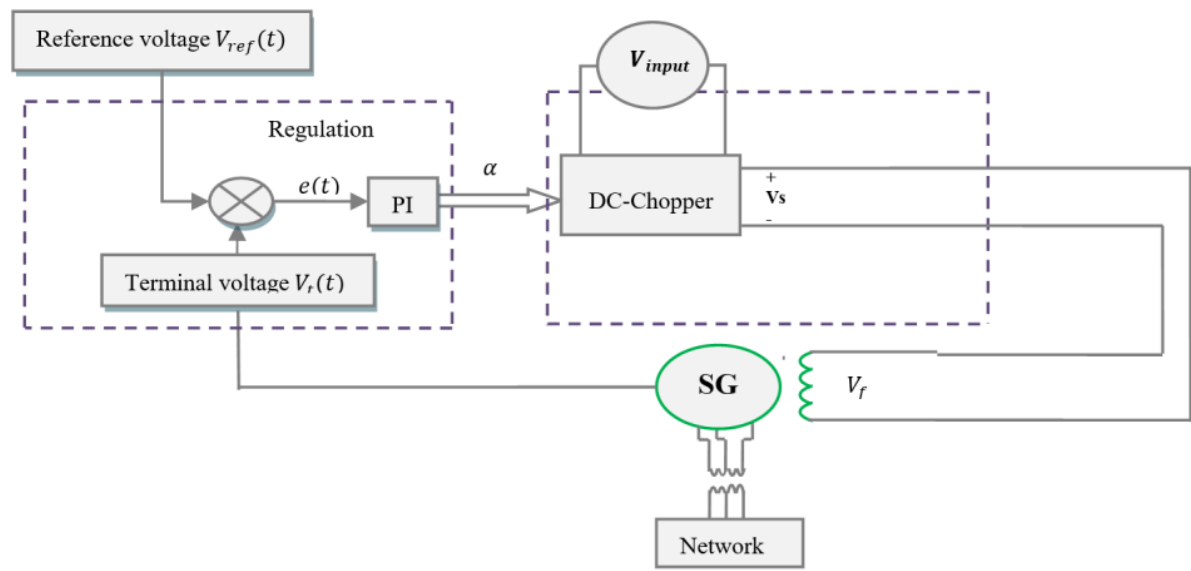

Figure 2. Block diagram of the proposed automatic voltage regulator (AVR) with PI-controller

This block diagram contains a controller, a converter, a main power source of the converter and a synchronous generator. The generator field winding requires DC supply and it is adjusted by a DC chopper (buck type). The terminal voltage of the generator $\left(V_{t}(t)\right)$ is compared with the reference voltage $\left(V_{\text {ref }}(t)\right)$ to give the error $(e(t))$ as shown in (11).

$$
e(t)=V_{r e f}(t)-V_{t}(t)
$$

The duty cycle $\alpha$ of the DC-chopper is regulated by the PI-controller and the output voltage $V_{s}$ of the DC-chopper is given by(12) depending on the duty cycle $\alpha$ [19].

$$
V_{s}=\alpha \cdot V_{\text {input }}
$$


Where;

$V_{s}$ is the output of the DC-chopper or field voltage $\left(V_{f}\right)$ and $V_{\text {input }}$ is the supply voltage to the DC-Chopper. By controlling the duty cycle $\alpha$, the field voltage is adjusted to regulate the output of the generator.

\subsection{Proportional Integral controller (PI Controller)}

The PI controller consists of two parameters, the proportional gain, denoted $K_{p}$ and the integral gain, denoted $K_{i}$. Figure 3 shows the typical structure of PI controller.

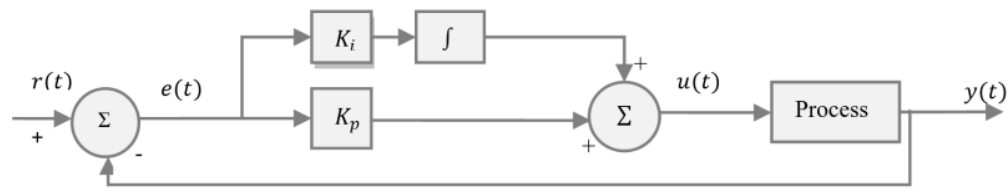

Figure 3. Basic block of proportional integral controller (PI controller)

The PI controller in the time domain is described by the relation [20]:

$$
u(t)=K_{p} e(t)+K_{i} \int_{0}^{t} e(t) d t
$$

where, $e(t)$ and $u(t)$ are tracking error and the control signals represented in the time domain.

The transfer function of this controller is represented in the following (14):

$$
u(s)=\left(K_{p}+\frac{K_{i}}{s}\right) e(s)
$$

\section{TUNING OF PI-CONTROLLER FOR OUTPUT VOLAGE REGULATION USING PSO APPROACH}

4.1. PSO Algorithm

Particle swarm optimization (PSO), developed by Eberhart and Kennedy [21] in 1995, is aswarm intelligence meta-heuristic inspired from the group behavior of animals, for example movement of bird flocks or fish schools [22] can be simulated. The algorithm starts by initializing a population of random solutions called particles and searches foroptima by updating generations through the following velocity and position update equations.

The new velocity of each particle is formulated by the relation:

$$
v_{i}(k+1)=w v_{i}(k)+c_{1} r_{1} \times\left(\operatorname{pbest}_{i}(k)-x_{i}(k)\right)+c_{2} r_{2} \times\left(\operatorname{gbest}(k)-x_{i}(k)\right)
$$

The position of each particle is updated in each generation according to the following expression:

$$
x_{i}(k+1)=x_{i}(k)+v_{i}(k+1)
$$

In (15) and (16), $v_{i}(k+1)$ is the new value of velocity vector, $v_{i}(k)$ is the previous velocity vector, $x_{i}(k+1)$ is the new position vector, $x_{i}(k)$ is the previous position vector, pbest $_{i}(k)$ is the particle's local best known position, and $g$ best $(k)$ is global best known position. $c_{1}$ and $c_{2}$ are positive constants called respectively coefficient of the self-recognition component and coefficient of the social component. $w$ is the inertia factor, $r_{1}$ and $r_{2}$ are random numbers between zero and one.

The parameter $w$ shall be properly set such that the impact of the previous velocity and the magnitude of the position shifts depends on the values of the parameters $c_{1}$ and $c_{2}$. Therefore, the choice of these parameters is very important for the convergence of this method. In the original PSO algorithm, the positive acceleration constants $c_{1}$ and $c_{2}$ are usually set between 0.5 and 2 [21].

\subsection{Implementation Of A PSO-PI controller}

The block diagram of PI controller tuned by PSO algorithm is shown in Figure 4. The principal objective of the PSO algorithm is to search the optimal value of $K_{p}$ and $K_{i}$ based on the objective function F, 
which is given by the relation (17). In this article, F represents the quadratic output error between the reference voltage and the terminal voltage calculated from the adopted model.

$$
F=\sum_{i=1}^{n}\left(V_{\text {refi }}-V_{t i}\right)^{2}
$$

Where $\mathrm{n}$ is the number of sampled points, $V_{r e f i}$ is the reference voltage, and $V_{t i}$ is the terminal voltage of the generator.

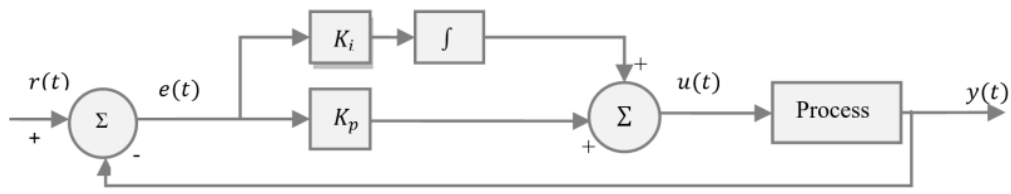

Figure 4. Block diagram of PI controller tuned by PSO

where;

$V_{\text {input }}:$ is the supply voltage to the DC-Chopper.

$V_{\text {ref }}=220 \mathrm{v}$ (r.m.s) is the fixed reference voltage.

In this paper, the terminal voltage is the max of the stator terminal voltage $V_{a s}(t)$. Note that the latter one is obtained by a numerical resolution of the non-linear system (6) by means of the fourth-order RungeKutta method using the parameters of the reference [23]. Figure 5 shows the flowchart of PI-PSO approach to regulate the terminal voltage of a synchronous generator. The parameters for the PSO algorithm are collected in Table 1.

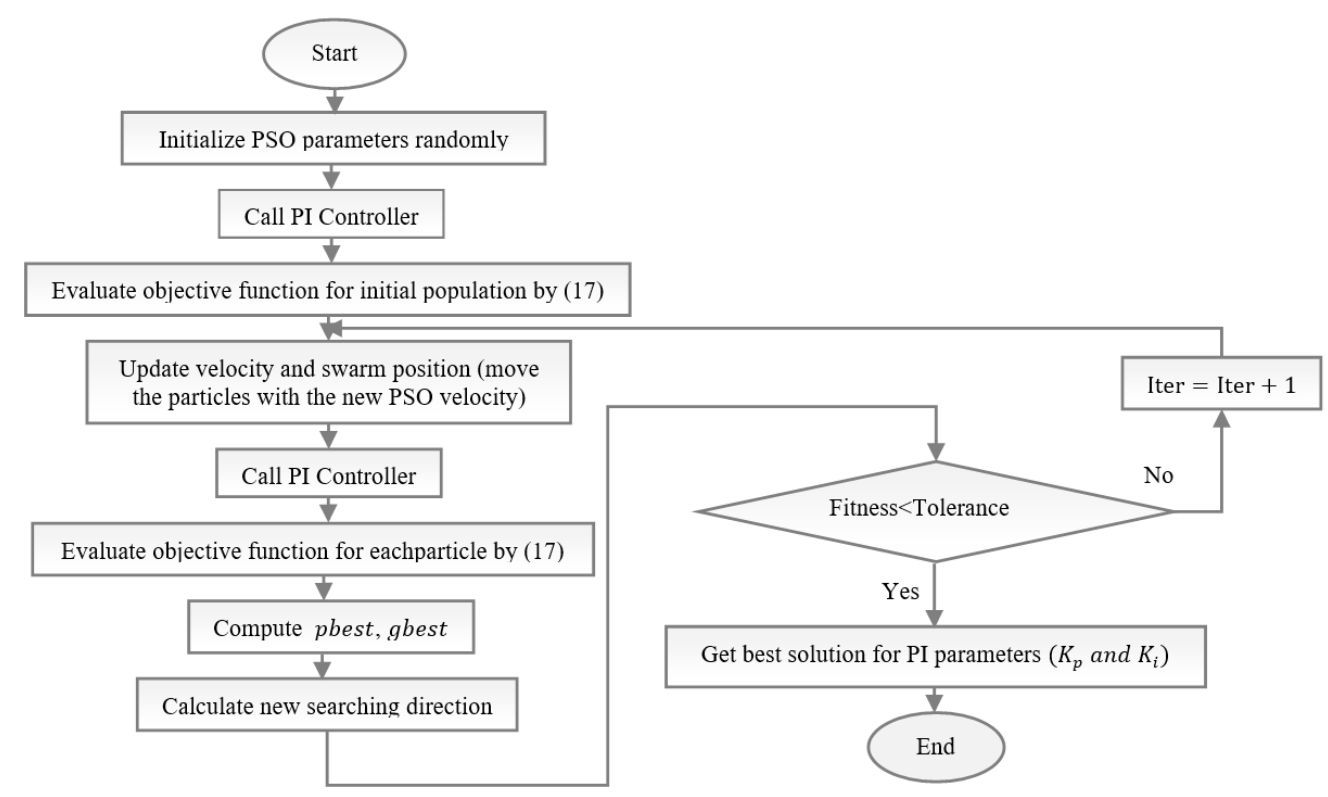

Figure 5. Flowchart of the PSO-PI controller

Table1. Parameters of PSO algorithm

\begin{tabular}{ll}
\hline \multicolumn{1}{c}{ PSO property } & Value \\
\hline Number of dimensions of the search space & 2 \\
Initial particles positions & Random \\
Population size & 10 \\
Inertia weight factor $w$ & 0.8 \\
Acceleration constant $c_{1}$ & 1.6 \\
Acceleration constant $c_{2}$ & 1.5 \\
Tolerance & $10^{-6}$ \\
\hline
\end{tabular}




\section{SIMULATION RESULTS AND DISCUSSION}

Three different loads are applied to the generator at different instant in order to show the impact of a load on the terminal voltage. Also, the generator loading conditions are:

- The generator starts with the inductive load $L_{1}$ characterized by $R_{L 1}=30 \Omega ; L_{L 1}=0.1 H$

- $\quad$ After one (01) second, the load $L_{2}\left(R_{L 2}=10 \Omega ; L_{L 2}=0.2 H\right)$ takes the relay.

- $\quad$ After (02 seconds), the load $L_{3}\left(R_{L 3}=80 \Omega ; L_{L 3}=0.1 H\right)$ is applied.

\subsection{Before regulation (without PI-controller)}

In this case, the field excitation voltage must be kept constant and the generator operates at rated synchronous speed $(\omega=157 \mathrm{rad} / \mathrm{s})$. Figure 6 shows the terminal voltage response of the SG before regulation (without PI-controller) for different loading conditions.

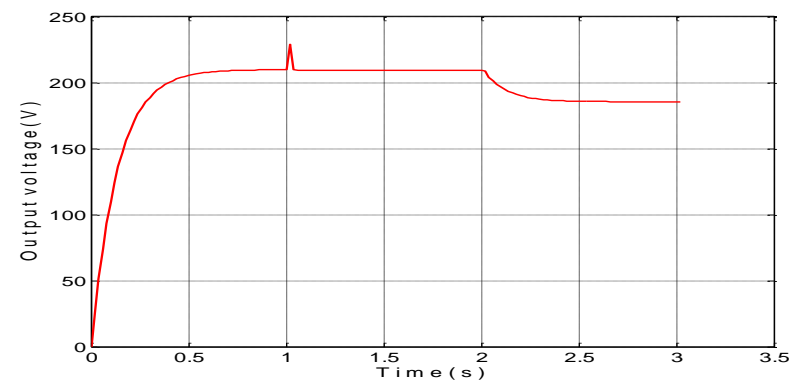

Figure 6. Output voltage response of the SG before regulation for different loading conditions.

As shown in Figure 6, the variation of the load connected to the generator has a direct influence on the voltage generated. Furthermore, the response time is large, as well as the voltage drop and the disturbances caused by the load changes.

\subsection{After regulation}

In this part, the reference voltage is taken at the value (Vref $=220 \mathrm{v}$ (r.m.s)). The regulation of the output voltage of the synchronous generator using the (PSO) algorithm is simulated by interaction between MATLAB and Simulink. In order to evaluate the performance of the PSO-PI controller, the same simulation is implemented using the genetic algorithm (GA) [24]. The parameters used in this study for the GA-PI controller are summarized in Table2. Note that, the lower and upper bound of the gains (Kp and $\mathrm{Ki}$ ) are the same for both algorithms. Table 3 provides the optimal gain parameters of the PI-controller tuned by GA and PSO algorithms. Figure 7 shows the superposition of the terminal voltage response of the SG with PI controller tuned by GA and by PSO through diverse loading conditions. The parameters (Kp and Ki) evolution versus the number of iterations is illustrated in Figure 8.

Table 2. Parameters of GA algorithm

\begin{tabular}{ll}
\hline \multicolumn{1}{c}{ GA property } & Value \\
\hline Number of dimensions of the search space & 2 \\
Initial population & Random \\
Population size & 10 \\
Crossover probability & 0.75 \\
Mutation probability & 0.06 \\
Tolerance & $10^{-6}$ \\
\hline
\end{tabular}

Table 3. PI controller gain values.

\begin{tabular}{ccccc}
\hline Controller type & $K_{p}$ & $K_{i}$ & Number of iterations & Time computing (sec) \\
\hline PSO-PI & 0.00815 & 0.72149 & 186 & 5252.8656 \\
GA-PI & 0.00809 & 0.71850 & 313 & 11428.5708 \\
\hline
\end{tabular}




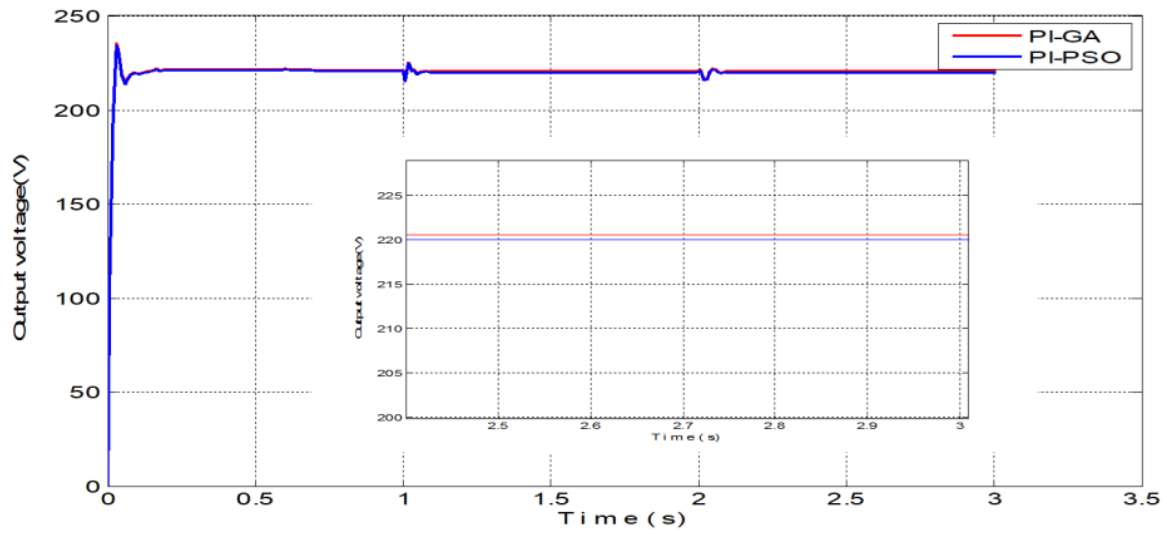

Figure 7. Superposition of the terminal voltage response of the SG with PI controller tuned by GA and by PSO through diverse loading conditions.

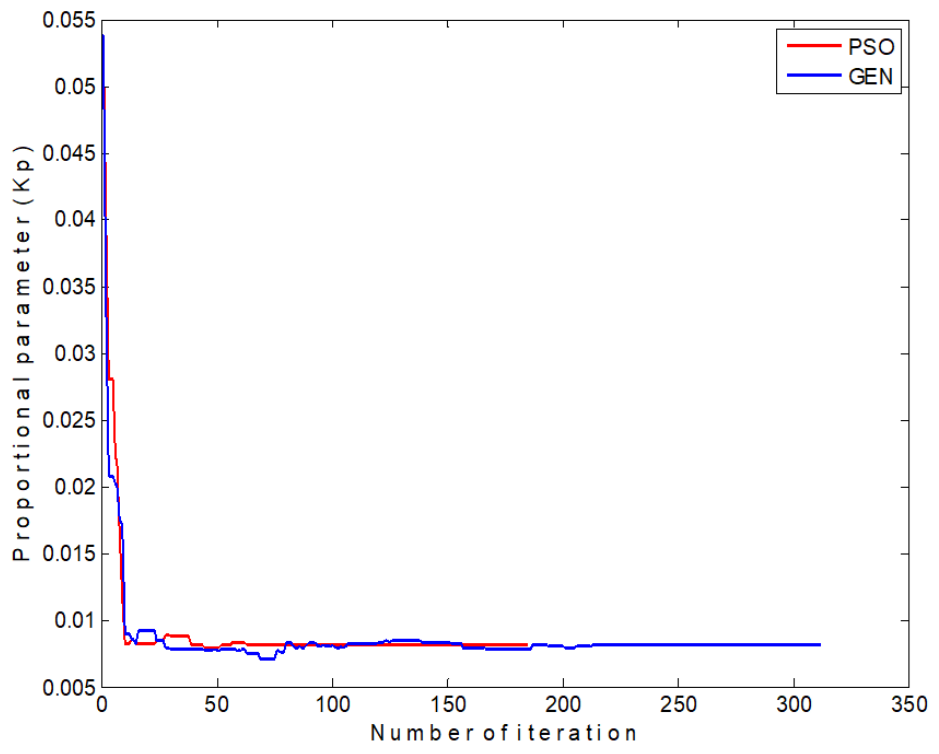

(a)

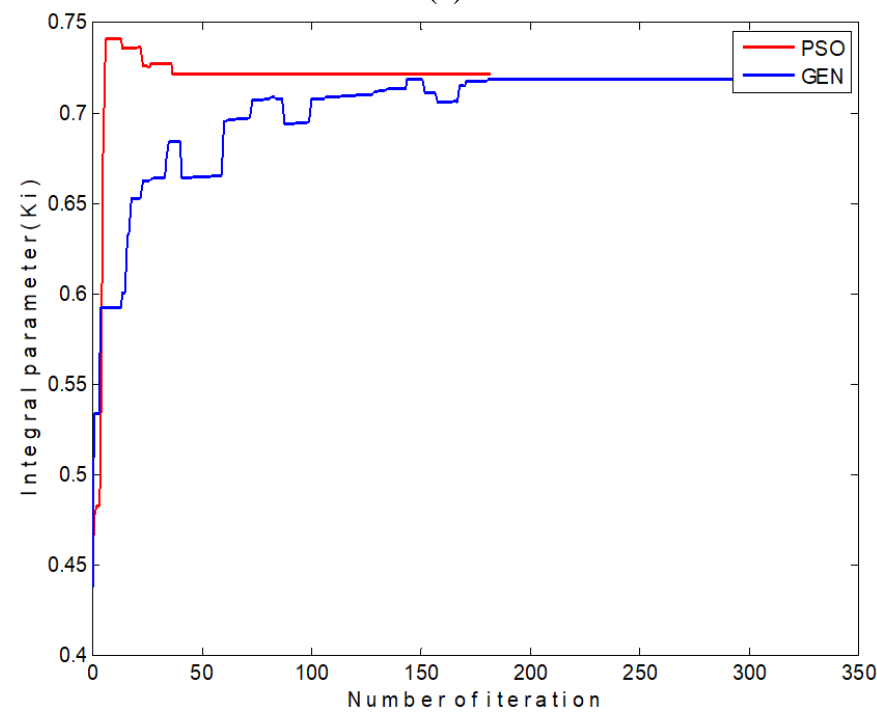

(b)

Figure 8. Parameters evolution of the PI-controller: (a) Kp, (b) Ki (solid red line: PSO, solid blue line: GA) 
As it can be seen in Table 3, the proximity of the PI-controller parameters (Kp and Ki) confirms well the convergence of the (GA) and the (PSO) algorithms. Furthermore, the PSO-PI controller consumes less time and has less iterations than the GA-PI controller as shown in Figure 8.However, the Figure 7proved that the overshoot resulting in the response of the terminal voltage of the generator is bigger.

In this study, The PSO algorithm is used to determine optimal parameters ( $\mathrm{Kp}$ and $\mathrm{Ki}$ ) of the PIcontroller, which regulates the duty cycle of the DC-chopper, as shown in Figure 9 to ensure the convergence of the terminal voltage of the generator to the desired value. The generator armature current in phase (a) during different loading conditions is plotted in Figure 10.

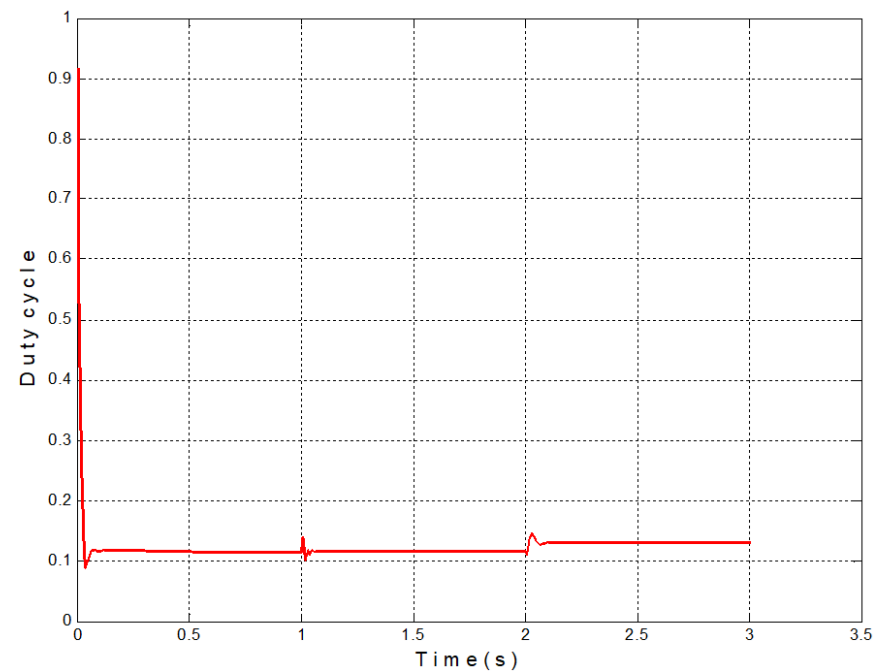

(a)

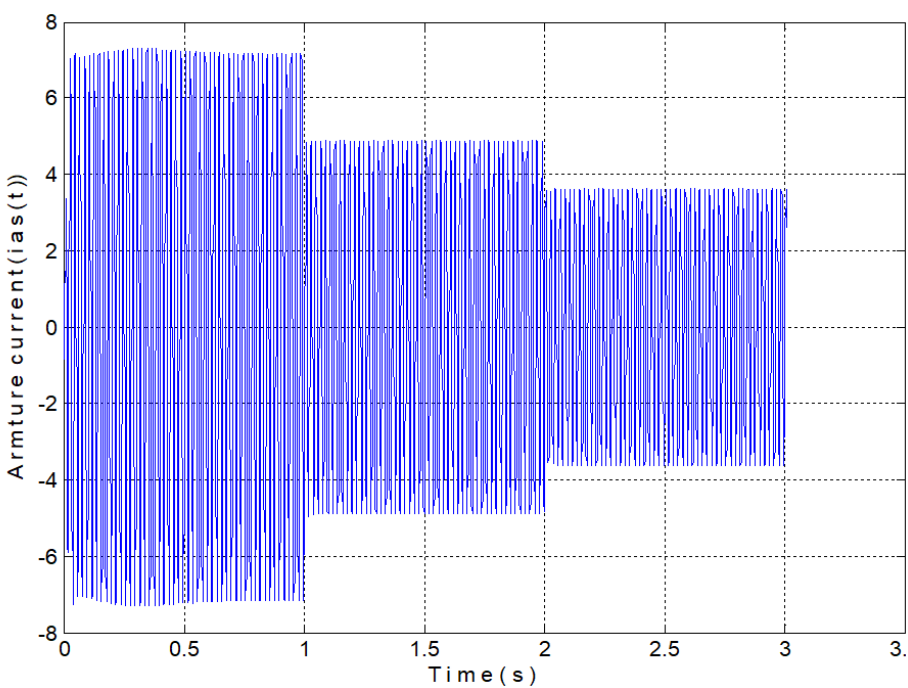

(b)

Figure 9.The duty cycle of the DC-chopper Figure 10. Generator armature current $\left(I_{a s}(t)\right)$

\subsection{Imrovement of the overshoot}

In order to reduce the overshoot resulting in the terminal voltage response of the SG, we adopted a varied reference voltage. In other words, the previous reference voltage (Vref $=220 \mathrm{v}$ (r.m.s)) is replaced with a ramp form during $t_{0}$ and continued with a constant voltage during $t-t_{0}$ as shown in Figure 11 . This improvement takes into consideration that the reference voltage does not suddenly go from zero to the maximum value of the set point, but it increases progressively until the voltage set point is reached. 


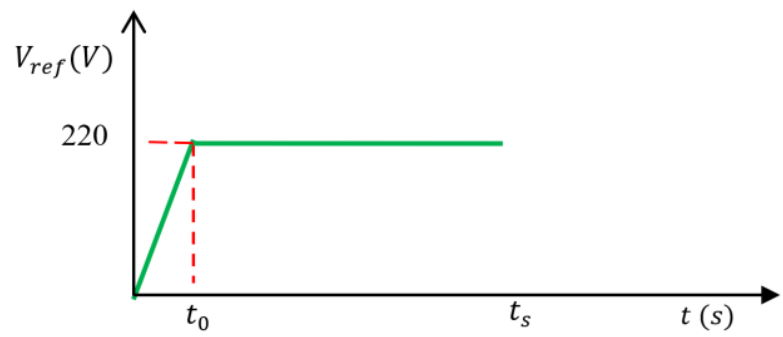

Figure 11. The varied reference voltage

where;

$t_{0}$ : is the ramp time corresponding to the time required to reach the generator voltage set point.

$t_{s}:$ is the simulated time.

The varied reference voltage can be expressed as (18):

$$
V_{\text {ref }}=\left\{\begin{array}{c}
\left(\frac{220}{t_{0}}\right) t t \leq t_{0} \\
220 t_{0}<t<t_{s}
\end{array}\right.
$$

In this case, $t_{0}$ takes the value 0.06s. After giving the same parameters settings above to the PSO algorithm, optimal PI controller parameters were obtained as shown in Table4. The comparative output voltage response of the generator using the PSO-PI controller with the fixed and the varied reference voltage is shown in Figure 12.

Table 4. Optimized parameters $\left(K_{p}\right.$ and $\left.K_{i}\right)$

\begin{tabular}{ccc}
\hline Gains coefficients & $K_{p}$ & $K_{i}$ \\
\hline Values & 0.0169 & 0.2805 \\
\hline
\end{tabular}

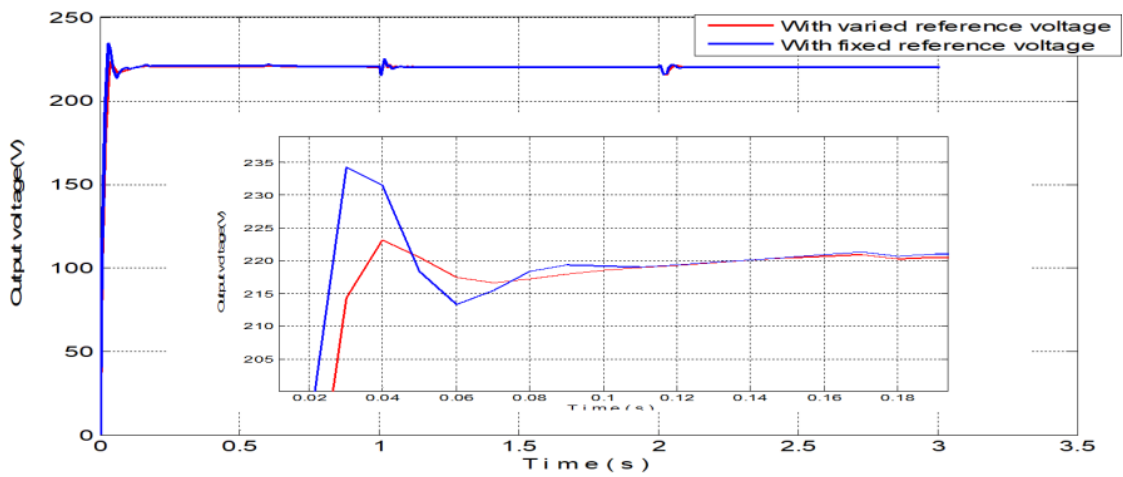

Figure 12. Comparison of the terminal voltage response

From the comparison shown in Figure 12, it can be seen that the terminal voltage response with varied reference voltage has small overshoot and short settling time compared to the terminal voltage response with a fixed reference voltage. The transient response specifications (overshoot percentage, the settling time and the rise time) are calculated using the relationship provided by the reference [25]. The comparative results obtained are summarized in Table 5.

Table 5. Comparison between the output voltage of the synchronous generator using the varied and the fixed reference voltage

\begin{tabular}{lcc}
\hline \multicolumn{1}{c}{ Parameters } & Varied reference voltage & Fixed reference voltage \\
\hline Overshoot percentage \% & 1.89 & 6.59 \\
Settling time (s) & 0.29 & 0.34 \\
Rise time (s) & 0.02 & 0.02 \\
\hline
\end{tabular}




\section{CONCLUSION}

This work presents a regulation of the output voltage of a synchronous generator using the nonlinear model of the SG. The PSO algorithm is utilized for the determination of the optimal parameters of the proportional integral (PI) controller. The latter one is used to adjust the duty cycle of the DC chopper for controlling the field voltage and consequently the output voltage of the generator. The performance of the PSO-PI controller is tested with the GA-PI controller. In terms of computational time and iteration number, the obtained results show the superiority of the PSO-PI controller versus the GA-PI controller but both the PSO-PI controller and the GA-PI controller produces a bigger overshoot in the terminal voltage response of the generator. To circumvent this problem, a varied reference voltage is chosen. The comparison between the terminal voltage response using the fixed and the varied reference voltage proves that the latter one has the capability to reduce the overshoot and also the settling time.

\section{REFERENCES}

[1] P. Kundur, Power System Stability and Control, New York: McGraw Hill, 1994.

[2] Wint Yu YuZaw, "Performance Analysis of Automatic Voltage Regulator in Power Generation System," International Journal of Science and Engineering Applications, volume 8, no. 07, pp.180-185, 2019, DOI: 10.7753/IJSEA0807.1003.

[3] A. Darabi, S.A. Soleamani and A. Hassannia, "Fuzzy Based Digital Automatic Voltage Regulator of a Synchronous Generator with Unbalanced Loads," American J. of Engineering and Applied Sciences, vol. 1, no. 4, pp.280-286, 2008, DOI: 10.3844/ajeassp.2008.280.286.

[4] G. A. Salman., A. S. Jafar and A.I. Ismaael, "Application of artificial intelligence techniques for LFC and AVR systems using PID controller," International Journal of Power Electronics and Drive System (IJEPDS), vol. 10, no. 3, pp. 1694-1704, 2019, DOI: 10.11591/ijpeds.v10.i3.pp1694-1704.

[5] A. T. Humod, "Study the Robustness of Automatic Voltage Regulator for Synchronous Generator Based on Neural Network," Iraqi Journal of Computers, communivation, Control and Systems Engineering (IJCCCE), vol. 13, no. 3, pp. 51-64, 2013.

[6] H. Gozde and M. C. Taplamacioglu, "Comparative performance analysis of artificial bee colony algorithm for automatic voltage regulator (AVR) system," Journal of the Franklin Institute, vol. 348, no. 8, pp. 1927-1946, 2011, DOI: 10.1016/j.jfranklin.2011.05.012.

[7] B. M. Atiyah, S. H. Yadgar and M. G. K. Alabdullah., "Comparison of MATLAB Simulink application with PLC application of real-time classical PID controllers in laboratory," Periodicals of Engineering and Natural Sciences, vol. 7, no. 4, pp. 2045-2056, 2019.

[8] U. Güvenç, T. Yiğit, A. H. Ișik and I. akkaya, "Performance analysis of biogeography-based optimization for automatic voltage regulator system," Turkish Journal of Electrical Engineering \& Computer Sciences, vol. 24, pp. 1150-1162, 2016, DOI:10.3906/elk-1311-111.

[9] A. Tripathi, R. L. Verma and Md. SanawerAlam, "Design of Ziegler Nichols Tuning Controller for AVR System," International Journal of Research in Electronics \& Communication Technology, vol. 1, no. 2, 2013, pp. 154-158, 2013.

[10] P. Govindan., "Evolutionary algorithms-based tuning of PID controller for an AVR system," International Journal of Electrical and Computer Engineering (IJECE), vol. 10, no. 3, pp. 3047-3056, 2020, DOI: ijece.v10i3.pp30473056.

[11] B. W. Hogg, Q. H. Wu and E. Swidenbank, "Optimal PID automatic voltage regulator for synchronous machines," International Journal of Control, vol. 50, no.6, pp. 2615-2634, 1989, DOI: 10.1080/00207178908953518.

[12] S. Vivekanandan, G. Saravanan, P. Kamalakannan and S. Krishnaprabhu, "Chaotic Differential evolution Algorithm based PID Controller for Automatic Voltage Regulator system," International Journal of Scientific and Research Publications, vol. 5, no. 6, 2015.

[13] T. Aljaifi, A. Abdellatif, A. Bawazir, O. Pauline, L. C. Yee and H. Abdullah, "Applying Genetic Algorithm to Optimize the PID controller Parameters for an Effective Automatic Voltage Regulator," Communications in Computational and Applied Mathematics, vol. 1, no. 2, pp. 10-15, 2019.

[14] N. A. Alawad and N. G. Rahman, "Tuning FPID Controller for an AVR System Using Invasive Weed Optimization Algorithm," Jordan Journal of Electrical Engineering, vol. 6, no. 2, pp. 128-139, 2020, DOI: 10.5455/jjee.2041581071239.

[15] E. Song, N. S. I. Albakirat and N. F. Mohammed, "Transient Response Enhancement of High Order Synchronous Machine based on Evolutionary PID controller," International Journal of Control and Automation, vol. 7, no. 12, pp. 383-398, 2014, DOI: 10.14257/ijca.2014.7.12.35.

[16] A. I. Al-Odienat, "The PID Controller Based on Genetic Algorithm for Voltage Stability of the Synchronous Machine," International Journal of Innovative Comuting, Information and Control, vol.10, no.6, pp. 2263-2276, 2014.

[17] J. Lesenne, G. Seguier, ando F. Notelet, Introduction à l'électrotechnique approfondie, Paris, France: Technique et Documentation, 1981.

[18] J. Chatelain, Machines électriques, vol. 10, Presses Polytech. Romandes: Traitéd'Electricité, 1989. 
[19] L. Y. Ghamri, H. Awadh, N. Al Shamsi, S. AlKhateri, A. Khurram and H. Rehman, "Robust AVR design for the synchronous generator," The 9th International Conference on Power Electronics, Machines and Drives (PEMD 2018), vol. 2019, no. 17, pp. 4111-4115, 2019, DOI: 10.1049/joe.2018.8114.

[20] M. A. Ibrahim, "Performance evaluation of PI controller for positive output Luo converter," International Journal of Power Electronics and Drive System (IJPEDS), vol. 11, no. 4, pp. 1816-1825, 2020, ijpeds.v11.i4.pp1816-1825.

[21] Russel C. Eberhart and James Kennedy, "A new optimizer using particle swarm theory," MHS'95. Proceedings of the Sixth International Symposium on Micro Machine and Human Science, 1995, pp. 39-43, DOI: 10.1109/MHS.1995.494215.

[22] Zwe-Lee Gaing, "A Particle Swarm Optimization Approach forOptimum Design of PID Controller in AVR System," IEEE Transactions on Energy Conversion, vol. 19, no. 2, pp. 384-391, 2004, DOI: 10.1109/TEC.2003.821821.

[23] L. Abdeldjalil, "Modélisation dynamique et commande des alternateurs couplés dans un réseau électrique embarqués," Ph.D. dissertation, Université deNantes, Français, 2006.

[24] E. Boudissa, M. Bounekhla, "A Real-Coded Genetic Algorithm Applied to Induction Machine Parametric Identification Trough an Output Error," The Mediterranean Journal of Measurement and Control, vol. 6, no. 3, pp. 109-119, 2010.

[25] D. Yadav and A. Verma, "ComperativePerformace Analysis of PMSM Drive Using MPSO and ACO Techniques," International Journal of Power Electronics and Drive System (IJEPDS), vol. 9, no. 4, pp. 1510-1522, 2018, DOI: 10.11591/ijpeds.v9.i4.pp1510-1522. 